\title{
MODEL Fe(III) PORPHYRIN SYSTEMS : AXIAL LIGATION IN OXIDIZED CYTOCHROME P-450.S
}

\author{
G. C. PAPAEFTHYMIOU, R. B. FRANKEL and S. FONER \\ Francis Bitter National Magnet Laboratory ( $\dagger$ ) Massachusetts \\ Institute of Technology, Cambridge, Massachusetts 02139, U. S. A.
}

and

\section{S. C. TANG $(*)$ and S. KOCH $(* *)$}

Department of Chemistry, Massachusetts Institute of Technology

Cambridge, Massachusetts 02139, U. S. A.

and

\section{R. H. HOLM}

Department of Chemistry, Stanford University, Stanford, California 94305, U. S. A.

\begin{abstract}
Résumé. - Nous avons préparé et étudié par la spectroscopie Mössbauer les composés modèles synthétiques de coordination axiale d'oxygène ( $\mathrm{Fe}(\mathrm{PPIXDME})(\mathrm{OEt})$ et $\mathrm{Fe}$ (PPIXDME) $\left(\mathrm{OC}_{6} \mathrm{H}_{4} \mathrm{NO}_{2}\right)$ ) et de soufre (Fe(PPIXDME) $\left(\mathrm{SC}_{6} \mathrm{H}_{4} \mathrm{NO}_{2}\right)$ et $\left.\mathrm{Fe}(\mathrm{OEP})(\mathrm{SPh})\right)$ pour développer des critères expérimentaux utiles à distinguer entre les possibilités des ligatures axiales viables de $\mathbf{O}, \mathbf{N}$ et $\mathbf{S}$ dans le cytochrome $\mathbf{P}-450$.S (à l'état ferrique, spin-fort). Nous avons fait usage d'hémoglobine et myoglobine ferriques comme composés modèles avec $\mathrm{N}-$ à la coordination axiale. Les déplacements isomériques $(\delta)$ et les éclatements quadrupolaires $\left(\Delta E_{Q}\right)$ observés sont typiques des porphyrines ferriques de spin-fort et comparables aux résultats pour cytochrome P-450.S oxydé. Cependant, ces paramètres ne présentent pas une dépendance caractéristique de la nature de la ligature axiale et ne peuvent pas être utilisés pour l'identification de la ligature axiale dans l'enzyme. Nous avons donc obtenu des spectres Mössbauer à la présence des champs magnétiques $\left(H_{0} \leqslant 120 \mathrm{kOe}\right)$ et mesures de magnétisation $\left(H_{0} \leqslant 60 \mathrm{kOe}\right)$ et nous les avons analysés supposant un hamiltonien de spin de la forme $\mathfrak{X}_{\theta}=D\left[S_{z}^{2}-\frac{1}{3} S(S+1)\right]+E\left(S_{x}^{2}-S_{y}^{2}\right)+2 \beta$ H.S pour évaluer les paramètres de champ crystallin, $D$ et $E$, et le champ magnétique hyperfin saturé, $H_{\text {hs }}^{0}$ dans la série des complexes de PPIXDME. $-H_{\mathrm{hP}}^{0} \geqslant 500 \mathrm{kOe}$ pour hémoglobine ferrique et des porphyrines de coordination axiale d'oxygène qui est considérablement plus grand que la valeur de $-450 \mathrm{kOe}$ observée pour le cytochrome $\mathrm{P}-450$. S oxydé. Seulement la valeur de $H_{\mathrm{h}}^{\mathrm{0}}$ pour le complexe de soufre Fe(PPIXDME) $\left(\mathrm{SC}_{6} \mathrm{H}_{4} \mathrm{NO}_{2}\right), H_{\mathrm{nf}}^{0}=-467 \pm 10 \mathrm{kOe}$, s'approche-t-elle de la valeur de $H_{\mathrm{hp}}^{0}$ obtenue pour l'enzyme. Aussi, les mesures de RPE et de magnétisation indiquent que les composés avec $\mathrm{O}-$ et $\mathrm{N}$ - comme ligatures axiales ont des symmétries axiale ou presque axiale pendant que $\mathrm{Fe}(\mathrm{PPIXDME})\left(\mathrm{SC}_{6} \mathrm{H}_{4} \mathrm{NO}_{2}\right)$ et $\mathrm{Fe}(\mathrm{OEP})(\mathrm{SPh})$ devient de symmétrie axiale, $E / D \simeq 0,05$, qui compare plus favorablement à l'inhabituellement grand degré de symmétrie rhombique, $E / D \simeq 0,087$, observé pour le cytochrome P-450.S oxydé. Ces observations supportent la désignation de $S$ comme la ligature axiale de cytochrome P-450.S oxydé.
\end{abstract}

Abstract. - In an effort to develop useful experimental criteria to distinguish among the viable axial ligation possibilities of $\mathrm{O}, \mathrm{N}$, and $\mathrm{S}$ coordination in oxidized cytochrome $\mathrm{P}-450 . \mathrm{S}$ (substratebound, high-spin), synthetic model compounds with $\mathrm{O}-$ (Fe(PPIXDME) (OEt) and Fe(PPIXDME) $\left.\left(\mathrm{OC}_{6} \mathrm{H}_{4} \mathrm{NO}_{2}\right)\right)$ and $\mathrm{S}-\left(\mathrm{Fe}(\mathrm{PPIXDME})\left(\mathrm{SC}_{6} \mathrm{H}_{4} \mathrm{NO}_{2}\right)\right.$ and $\left.\mathrm{Fe}(\mathrm{OEP})(\mathrm{SPh})\right)$ donor axial ligands were prepared and studied by Mössbauer spectroscopy. Ferric hemoglobin and myoglobin were used as model compounds with $\mathrm{N}$-axial coordination. The isomer shifts $(\delta)$ and quadrupole splittings $\left(\Delta E_{Q}\right)$ observed are typical of high-spin Fe(III) porphyrins and are comparable with results for ox-P-450.S. However, these parameters do not exhibit a clearcut dependence on the nature of the axial ligand and cannot be used for identification of enzyme ligation. Mössbauer spectra in

(*) Present address : Shell Development Company Bel Aire Laboratory Houston, Texas, U. S. A.

(**) Present address : Department of Chemistry, Texas A \& M College Station, Texas, U. S. A. 
external magnetic fields $\left(H_{0} \leqslant 120 \mathrm{kOe}\right)$ together with magnetization measurements $\left(H_{0} \leqslant 60 \mathrm{kOe}\right)$ were, therefore, obtained and analyzed assuming a spin-Hamiltonian,

$$
\mathfrak{H}_{\mathrm{e}}=D\left[S_{z}^{2}-\frac{1}{3} S(S+1)\right]+E\left(S_{x}^{2}-S_{y}^{2}\right)+2 \beta \mathbf{H . S},
$$

in order to obtain estimates of the crystal field parameters, $D$ and $E$, and the saturation magnetic hyperfine field, $\mathbf{H}_{\mathrm{h}}^{0}$, in the PPIXDME series. For ferric myoglobin and the oxygen-ligated porphyrins - $\mathbf{H}_{\mathrm{hP}}^{0} \geqslant 500 \mathrm{kOe}$, considerably larger than the value of $-450 \mathrm{kOe}$ observed for ox-P-450.S. Only in the thiolate complex Fe(PPIXDME) $\left(\mathrm{SC}_{6} \mathrm{H}_{4} \mathrm{NO}_{2}\right)$ for which $-\mathrm{H}_{\mathrm{hP}}^{0}=476 \pm 10 \mathrm{kOe}$ is the enzyme value reasonably closely approached. In addition, magnetization and EPR measurements show that complexes with $\mathrm{O}-$ and $\mathrm{N}$ - donor ligands have axial or near axial symmetry while $\mathrm{Fe}$ (PPIXDME) $\left(\mathrm{SC}_{6} \mathrm{H}_{4} \mathrm{NO}_{2}\right)$ and $\mathrm{Fe}(\mathrm{OEP})(\mathrm{SPh})$ show deviations from axial symmetry with $E / D \simeq 0.05$, which compares more favorably with the unusually large degree of rhombicity, $E / D \simeq 0.087$, observed for ox-P-450.S. These observations support the designation of cysteinate sulfur as the axial ligand in ox-P-450.S.

1. Introduction. - Cytochrome P-450 monoxygenase (mixed-function oxidase) enzymes occur in mammalian microsomes and mitochondria as membrane bound compounds and in bacteria as soluble components [1, 2]. Important clues about their catalytic activity were originally obtained from spectroscopic studies on membrane bound cytochromes but clarifcation of many important questions was only made possible by studying the in vitro reconstituted cytochrome P-450 enzyme system from Pseudomonas putida [2]. Five different reaction states of the latter enzyme ( $\left.\mathrm{P}-450_{\text {cam }}\right)$ have been identified [2]. During its catalytic action of hydroxylation of carbon-hydrogen bonds the heme iron, contained in the protoporphyrin IX prosthetic group of the enzyme undergoes changes in oxidation and spin state and acquires all four possible states commonly observed in heme proteins (i. e., $\mathrm{Fe}(\mathrm{III}) ; S=\frac{1}{2}, S=\frac{5}{2}$ and $\mathrm{Fe}(\mathrm{II}) ; S=0, S=2$ ). These have been isolated and studied separately by a variety of physical methods including Mössbauer spectroscopy [3].

Among the physical properties of cytochrome P-450, two seem to be rather unusual for a heme protein: 1) the Soret absorption band of its $\mathrm{CO}$ complex peaks at a wavelength of $450 \mathrm{~nm}$ (from which it derives its name) rather than the usual $420 \mathrm{~nm}$ of other $\mathrm{CO}$ complexed heme proteins and 2) an unusually high (for heme proteins) degree of rhombicity of the iron environment as detected by EPR studies [4]. These observations have led to the speculation that an unusual ligand to the iron must be involved. In the absence of $x$-ray diffraction structural information, the nature of the axial ligand(s) in any of the reaction states has not been definitely identified. Indirect evidence, such as inactivation of microsomal P-450 cytochromes by sulfhydryl reagents [5] and observation of EPR $g$-values for thiol-treated acid met $\mathrm{Mb}, \mathrm{Hb}$ and hemin $[6,7]$ close to those of low spin cytochrome P-450, has led to the suggestion that a sulfur ligand is involved. Consideration of the known amino acid composition of $P$. putida $\mathrm{P}-450_{\text {cam }}$ and a liver microsomal cytochrome P-450 [8] reveals that among the amino acid residues available there is a number of potential ligating groups to the heme iron such as $-\mathrm{CH}_{2} \mathrm{SH},-\mathrm{CH}_{2} \mathrm{SMe}$, $-\mathrm{COOH},-\mathrm{C}_{6} \mathrm{H}_{4} \mathrm{OH},-\mathrm{CONH}_{2},-\mathrm{CH}_{2} \mathrm{OH}$, imi- dazolyl, and $-\mathrm{CH}_{2} \mathrm{NH}_{2}$. These could result in a coordination of an $\mathrm{S}$-, an $\mathrm{O}$ - or an $\mathrm{N}$-atom to the iron. The present investigation addresses the question of the nature of the axial ligation in high-spin Fe(III) cytochrome P-450 by studying synthetic heme model compounds with S- or $\mathrm{O}-$ axial ligand coordination. Ferric myoglobin and hemoglobin were used as model compounds with N-coordination because no stable synthetic high-spin $\mathrm{Fe}$ (III) complex with one $\mathrm{N}$-bonded axial ligand could be prepared.

Synthetic model compounds for the oxidized cytochrome P-450.S (substrate-bound, high-spin) with O-donor axial ligands, Fe(PPIXDME) (OEt) and $\mathrm{Fe}(\mathrm{PPIXDME})\left(\mathrm{OC}_{6} \mathrm{H}_{4} \mathrm{NO}_{2}\right)$, and S-donor axial ligands, $\mathrm{Fe}(\mathrm{PPIXDME})\left(\mathrm{SC}_{6} \mathrm{H}_{4} \mathrm{NO}_{2}\right)$ and $\mathrm{Fe}(\mathrm{OEP})$ $(\mathrm{SPh})$ were prepared [9] and studied by Mössbauer spectroscopy in the presence of high applied magnetic fields. (PPIXDME is protoporphyrin IX dimethyl ester dianion and OEP is octaethylporphyrin dianion.) In addition, measurements of the induced magnetization in applied magnetic fields were obtained and analyzed simultaneously with the Mössbauer results. The combination of these two measurements provides a means for determining the electronic ground state fine structure splitting of the heme iron and obtaining an estimate of the degree of covalency of the iron-ligand bond from the saturation magnetic hyperfine field at the iron nucleus. As discussed below, we find the fine structure splitting (both magnitude and rhombicity) and the magnetic hyperfine interaction constant to be sensitive to the nature of the axial ligand. Because of the predominant high-spin character of substrate-bound oxidized P-450 enzymes [3] and the correlation between the $S=\frac{5}{2}$ ground state in synthetic Fe(III) porphyrins and pyramidal coordination [10], this geometry is most likely for the substrate-bound reaction state. Accordingly, synthetic porphyrin complexes examined here are five-coordinate and all have been shown to be highspin from magnetic susceptibility measurements [9].

2. Experimental. - Details of the preparation, chemical and physical characterization, and x-ray crystal structure determination of the compounds under investigation have been given elsewhere [9]. Mössbauer spectra were recorded on a 512-channel analyzer using 
a constant acceleration Mössbauer drive, calibrated with metallic iron absorbers. Spectra were taken at $4.2 \mathrm{~K}, 77 \mathrm{~K}$ and room temperature. Longitudinal external magnetic fields were employed using a $\mathrm{Nb}-\mathrm{Sn}$ superconducting magnet up to $80 \mathrm{kOe}$ and a Bitter electromagnet for fields up to $122 \mathrm{kOe}$. A $100 \mathrm{mCi}{ }^{5.7} \mathrm{Co}$ (in Rh matrix) source was situated in zero field at the same temperature as the absorber. Three to $5 \mathrm{mg}$ of $\mathrm{Fe} / \mathrm{cm}^{2}$ thick absorbers were used resulting on the average in 6 to $10 \%$ effects. Mössbauer parameters were obtained by fitting the Mössbauer: spectra to Lorentzian lines except for cases of very broad line spectra that largely deviated from Lorentzians.

Magnetization measurements at $4.2 \mathrm{~K}$ over a magnetic field range from zero to $55 \mathrm{kOe}$ were obtained using a vibrating sample magnetometer adapted to a superconducting solenoid. Sample weights of the order of 20 to $50 \mathrm{mg}$ were used in thin-walled Delrin (plastic) containers. Corrections for any paramagnetism of the empty containers and the diamagnetism of the samples were taken into account, but for the strongly paramagnetic samples studied these corrections were negligible.

3. Results and discussion. - Figure 1 shows the inner coordination sphere of the iron atom in $\mathrm{Fe}(\mathrm{PPIXDME})\left(\mathrm{SC}_{6} \mathrm{H}_{4} \mathrm{NO}_{2}\right)$ [9]. The iron atom is displaced by $0.448 \AA$ out of the mean porphyrin plane and $0.434 \AA$ out of the $\mathrm{N}_{4}$ plane toward the axial sulfur atom. The plane of the $\mathrm{C}_{6} \mathrm{H}_{4} \mathrm{NO}_{2}$ ring bound to the sulfur atom is nearly parallel to the porphyrin ring plane forming a dihedral angle of $11.1^{\circ}$ with it. The basic structure of the other model heme compounds studied is similar to that of

$$
\mathrm{Fe}(\mathrm{PPIXDME})\left(\mathrm{SC}_{6} \mathrm{H}_{4} \mathrm{NO}_{2}\right)
$$

with the $\mathrm{S}$ atom replaced by an $\mathrm{O}$ atom in

$$
\mathrm{Fe}(\mathrm{PPIXDME})\left(\mathrm{OC}_{6} \mathrm{H}_{4} \mathrm{NO}_{2}\right)
$$

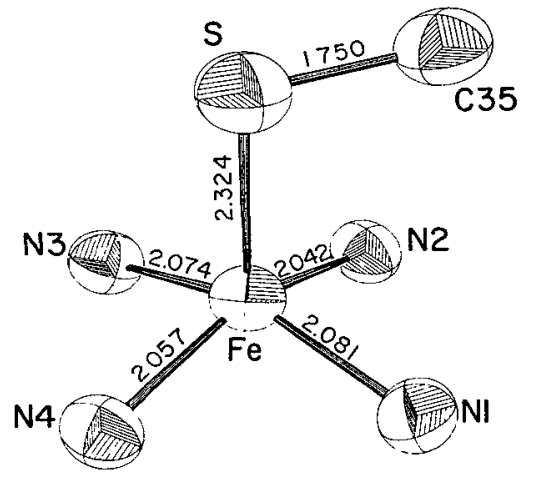

FIG. 1. - Coordination of the iron atom in Fe(PPIXDME) $\left(\mathrm{SC}_{6} \mathrm{H}_{4} \mathrm{NO}_{2}\right.$ ) (after ref. [9]).

and

\section{Fe(PPIXDME) (OEt).}

Additional details of the structure are given elsewhere [9].

The Mössbauer spectra of all complexes are characterized by a single quadrupole doublet with practically temperature independent quadrupole splittings $\left(\Delta E_{\mathrm{Q}}\right)$ and isomer shifts $(\delta)$. Mössbauer parameters are tabulated in table I. For $\mathrm{Fe}$ (PPIXDME) $\left(\mathrm{SC}_{6} \mathrm{H}_{4} \mathrm{NO}_{2}\right)$ and $\mathrm{Fe}$ (PPIXDME) $\left(\mathrm{OC}_{6} \mathrm{H}_{4} \mathrm{NO}_{2}\right)$ values of $\delta$ and $\Delta E_{\mathrm{Q}}$ typical of high-spin $\mathrm{Fe}$ (III) $\mathrm{N}_{4} \mathrm{~L}$ ( $\mathrm{L}=$ axial ligand) complexes are obtained. As shown in figure 2 , the spectrum in each case consists of a symmetric doublet at $4.2 \mathrm{~K}$. As the temperature is raised one of the components broadens resulting in an asymmetric doublet. This behavior is similar to that observed by previous investigators $[11,12]$ for synthetic and biological ferrihemes, and is due to electron spin relaxation effects with relaxation times increasing at higher temperatures because of thermal population of more slowly relaxing spin levels [13]. A comparison of the Mössbauer spectra shown in figure 2 indicates that for two of the com-

TABLE I

\begin{tabular}{|c|c|c|c|c|c|}
\hline Compound & $\begin{array}{c}\delta \\
\mathrm{mm} / \mathrm{s}\left(^{a, b}\right)\end{array}$ & $\begin{array}{c}\Delta E_{\mathrm{Q}} \\
\mathrm{mm} / \mathrm{s}\left({ }^{b}\right)\end{array}$ & $H_{\mathrm{hf}}^{0}, \mathrm{kOe}\left(^{b}\right)$ & $D, \mathrm{~cm}^{-1}$ & $E / D$ \\
\hline $\mathrm{Fe}(\mathrm{PPIXDME})\left(\mathrm{SC}_{6} \mathrm{H}_{4} \mathrm{NO}_{2}\right)$ & $0.33 \pm 0.03$ & $0.76 \pm 0.05$ & $-476 \pm 10$ & $10 \leqslant D \leqslant 12$ & $\leqslant 0.08$ \\
\hline$\left(\mathrm{CH}_{2} \mathrm{Cl}_{2}\right.$ soln. $)$ & $0.32 \pm 0.03$ & $0.88 \pm 0.05$ & & & \\
\hline $\mathrm{Fe}(\mathrm{OEP})(\mathrm{SPh})$ & $0.31 \pm 0.03$ & $0.49 \pm 0.05$ & & & \\
\hline $\mathrm{Fe}(\mathrm{PPIXDME})\left(\mathrm{OC}_{6} \mathrm{H}_{4} \mathrm{NO}_{2}\right)$ & $0.30 \pm 0.03$ & $0.74 \pm 0.05$ & $-495 \pm 5$ & $6.6 \pm 0.2$ & $\sim 0$ \\
\hline$\left(\mathrm{CH}_{2} \mathrm{Cl}_{2}\right.$ soln $)$ & $0.33 \pm 0.03$ & $0.98 \pm 0.05$ & & & \\
\hline $\mathrm{Fe}(\mathrm{PPIXDME})(\mathrm{OEt})$ & $0.32 \pm 0.03$ & $0.46 \pm 0.05$ & $-523 \pm 8$ & $5.3 \pm 0.2$ & $\leqslant 0.05$ \\
\hline acid-met $\mathrm{Mb}\left({ }^{c, d}\right)$ & 0.4 & $1.3\left(^{d}\right)$ & $-498 \pm 4$ & $9.5 \pm 1.5\left(^{e}\right)$ & \\
\hline $\mathrm{Fe}(\mathrm{PPIX}) \mathrm{Cl}\left({ }^{c}\right)$ & 0.35 & 0.75 & $-480\left({ }^{f}\right)$ & $7\left({ }^{e}\right)$ & $\sim 0$ \\
\hline ox-P-450.S $\left({ }^{g}\right)$ & 0.35 & 0.79 & $-448 \pm 10$ & $3.8\left(^{h}\right)$ & $0.082\left(^{h}\right)$ \\
\hline
\end{tabular}

Mössbauer Data for High-Spin Fe(III) Porphyrin Complexes

$\left({ }^{a}\right)$ Relative to Fe metal ; $\left(^{b}\right)$ Values at $4.2 \mathrm{~K}$ unless otherwise specified ; $\left(^{(}\right) 195 \mathrm{~K} ;\left({ }^{(}\right)$Ref. [11]; $\left({ }^{e}\right)$ Ref. $[19] ;(f)$ Ref. [16] ; $\left({ }^{g}\right)$ Ref. [3] ; $\left({ }^{h}\right)$ Rế. [4]. 


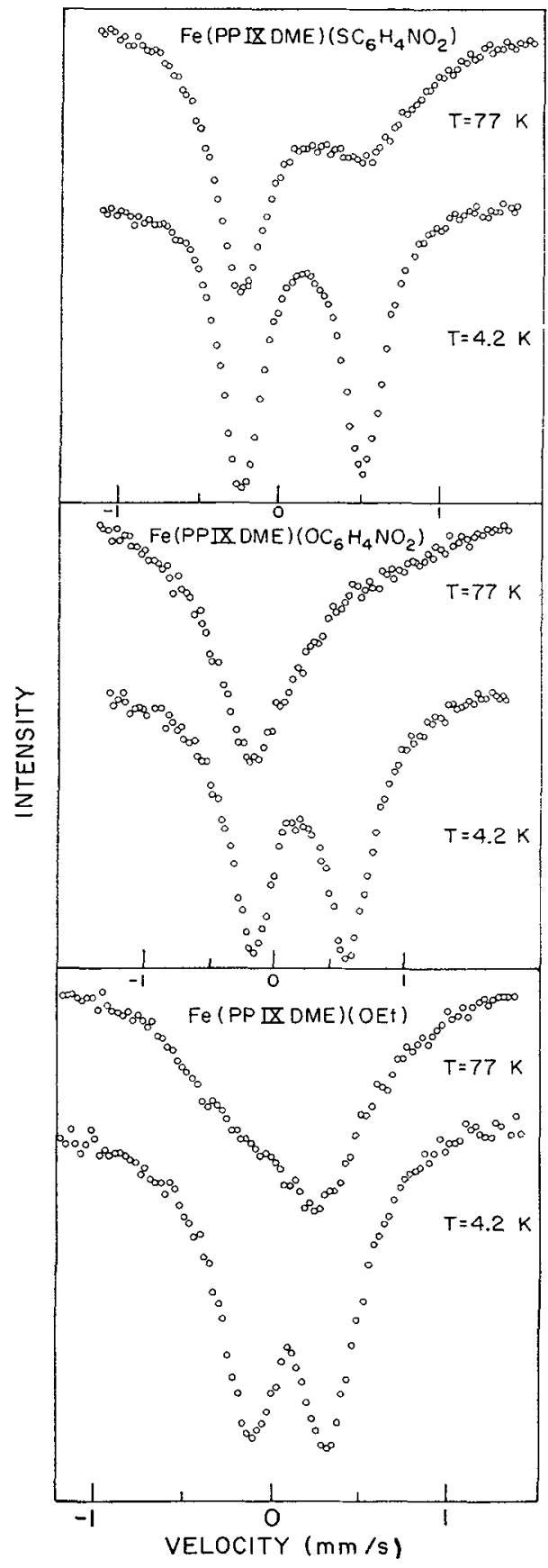

FIG. 2. - Mössbauer spectra of three high-spin Fe(III) porphyrins at $77 \mathrm{~K}$ and $4.2 \mathrm{~K}$.

plexes, namely, $\mathrm{Fe}$ (PPIXDME) $\left(\mathrm{OC}_{6} \mathrm{H}_{4} \mathrm{NO}_{2}\right)$ and $\mathrm{Fe}(\mathrm{PPIXDME})\left(\mathrm{SC}_{6} \mathrm{H}_{4} \mathrm{NO}_{2}\right)$ it is the higher velocity component that broadens with increasing temperature while for Fe(PPIXDME) (OEt) the asymmetry is reversed. This indicates that the sign of the principal component, $V_{z z}$, of the electric field gradient tensor (EFG) is positive for the first two compounds and negative for the latter. This negative sign of $V_{z z}$ for $\mathrm{Fe}(\mathrm{PPIXDME})(\mathrm{OEt})$ is also reflected in the magnetically split Mössbauer spectra discussed below. According to calculations by Sharma and Moutsos [14], based on linear combinations of polarized atomic orbitals, an increase in the value of the polarizability of the axial ligand, with the polarizability of the in-plane ligands unchanged, decreases $V_{z z}$ which eventually passes from a positive to a negative value. The experimental observation of a negative $V_{z z}$ in $\mathrm{Fe}$ (PPIXDME) (OEt) can be understood on the basis of these calculations if the polarizability of OEt is assumed to be higher than that of $\mathrm{OC}_{6} \mathrm{H}_{4} \mathrm{NO}_{2}$ or $\mathrm{SC}_{6} \mathrm{H}_{4} \mathrm{NO}_{2}$.

Values of $\delta$ and $\Delta E_{Q}$ are characteristic of the valence and spin state of the iron atom but within the same valence and spin state no clear cut dependence of these parameters on the nature of the axial ligand is observed. Consequently, no conclusion bearing on the type of axial ligation can be drawn by a comparison of these results with those obtained for $P$. putida P-450.S (Table I), the only cytochrome P-450 thus far studied by Mössbauer spectroscopy. Spectra in external magnetic fields as well as magnetization measurements were, therefore, obtained and analyzed in an attempt to develop useful criteria for identification of axial ligands in the PPIXDME series. These criteria are based on the effect of the axial ligand on the zero field splitting of the electronic ground state and the magnetic hyperfine structure constant of $\mathrm{Fe}(\mathrm{III})$.

Figure 3 shows typical Mössbauer spectra obtained for solid absorbers of the model heme complexes in the

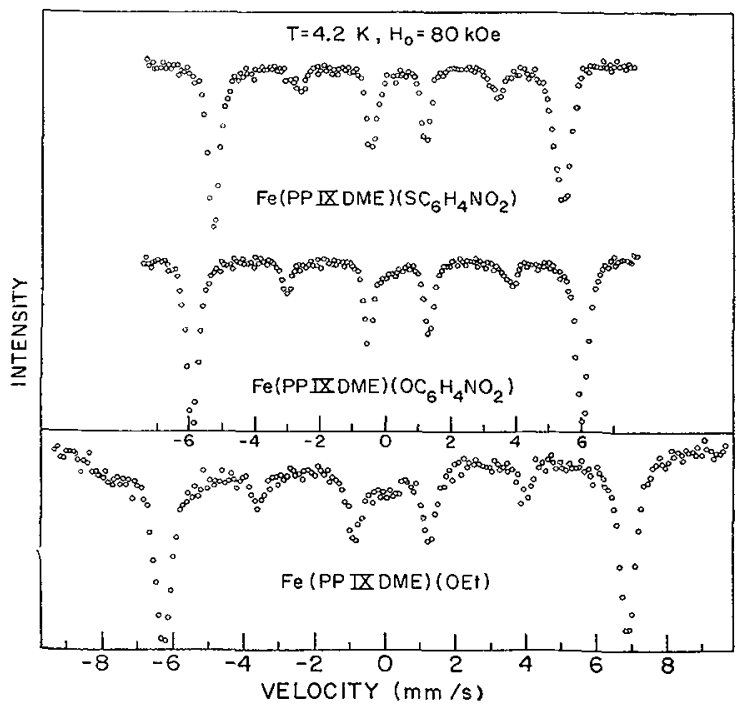

Fig. 3. - Mössbauer spectra of the porphyrin systems of figure 2 in a longitudinal magnetic field of $80 \mathrm{kOe}$.

presence of an externally applied magnetic field of $80 \mathrm{kOe}$ in longitudinal configuration. The large overall magnetic splitting of the outer lines of $\sim 12 \mathrm{~mm} / \mathrm{s}$ reveals that a large magnetic hyperfine interaction is induced by the applied field. Furthermore, the fact that sharp absorption lines are observed for powder absorbers indicates that the hyperfine field is induced in fixed directions, i. e., that the system has easy axes of magnetization. In addition, because residual $\Delta m=0$ lines are 
also observed these directions are not strictly parallel to the applied magnetic field.

The above observations are common to high spin ferric heme complexes and are the result of the low symmetry crystalline environment in which the iron atom is situated. In the presence of such a low symmetry crystalline field the six-fold spin degeneracy of the $\mathrm{Fe}^{3+}$ ion ground electronic state, ${ }^{6} \mathrm{~A}_{1}$, is partially lifted via the spin-orbit interaction with higher excited states [15]. Through the same interaction the isotropic magnetic hyperfine tensor expected for a $\mathrm{d}^{5}$ shell, arising primarily from the Fermi contact interaction, becomes anisotropic [11]. For fast relaxing electronic spin levels the magnetic hyperfine interaction experienced by the nucleus is determined by the average value of the electronic spin which is given by

$$
\langle\mathrm{S}\rangle=\frac{\sum_{i=1}^{6}<\alpha_{i}|S| \alpha_{i}>\mathrm{e}^{-E_{i} / k T}}{\sum_{i=1}^{6} \mathrm{e}^{-E_{i} / k T}}
$$

where the summation goes over the eigenstates $\left|\alpha_{i}\right\rangle$ of the spin Hamiltonian

$$
\begin{aligned}
\mathscr{H}_{c}=D\left[S_{z}^{2}-\frac{1}{3} S(S\right. & +1)]+ \\
& +E\left(S_{x}^{2}-S_{y}^{2}\right)+2 \beta \mathbf{H}_{0} \cdot \mathbf{S}
\end{aligned}
$$

within the six-fold spin multiplet of the ground electronic state $\left|S=\frac{5}{2}\right\rangle$ of the iron atom. The zero field splitting, $D$, gives a measure of the axial component of the crystalline field and $E / D$ determines the degree of rhombic distortion. In the strong axial crystalline field observed in most high spin ferric porphyrins $\left(D \sim 5\right.$ to $10 \mathrm{~cm}^{-1}$ ) the electron spins tend to align in the plane perpendicular to the $z$-axis [16]. Thus $\langle\mathbf{S}\rangle$ lies in the heme plane, $\left\langle\mathbf{S}_{\perp}\right\rangle$, and has a magnitude largely independent of the orientation of $\mathbf{H}_{0}$ relative to the $z$-axis.

The effective magnetic field at the nucleus is given by the vector sum of the applied and induced magnetic fields

$$
\mathbf{H}_{\mathrm{eff}}=\mathbf{H}_{\mathbf{0}}+\mathbf{H}_{\mathrm{hf}}
$$

with $\mathbf{H}_{\mathrm{hf}}=H_{\mathrm{hf}}^{0}\left[<\mathbf{S}_{\perp}>/ S\right]$ where $<\mathbf{S}_{\perp}>/ S$ gives the expectation value of the spin in units of its saturation value $S=\frac{5}{2}$ and $H_{\mathrm{hf}}^{0}$ is the saturation magnetic hyperfine field and is related to the magnetic hyperfine structure constant, $\mathbf{A}$, that appears in the nuclear part of the Hamiltonian :

$$
\begin{aligned}
\mathscr{H}_{\mathrm{N}}= & \frac{\mathrm{e} Q V_{z z}}{4 I(2 I-1)}\left[3 I_{z}^{2}-I(I+1)+\right. \\
& \left.+3 \eta\left(I_{x}^{2}-I_{y}^{2}\right)\right]-g_{\mathrm{N}} \mu_{\mathrm{N}} \mathbf{I} \cdot \mathbf{H}_{0}+\mathbf{I} \cdot \mathbf{A} \cdot \mathbf{S}
\end{aligned}
$$

where $Q$ is the quadrupole moment of the excited state of ${ }^{57} \mathrm{Fe}, V_{z z}$ is the principal component of the EFG and $\eta$ its asymmetry parameter. For the ground nuclear state $Q=0$ and the nuclear part of the Hamiltonian reduces to the last two terms of eq. (4).

Mössbauer spectra were obtained over a range of applied field strengths from 20 to $122 \mathrm{kOe}$ parallel to the $\gamma$-ray direction, and the effective magnetic field at the nucleus $\mathbf{H}_{\text {eff }}$ was obtained from the overall splitting of the Mössbauer spectrum. Below $30 \mathrm{kOe}$ most samples gave poorly resolved broad line spectra. Typical spectra at $80 \mathrm{kOe}$ are shown in figure 3 . The position of the $\Delta m=0$ lines is determined by the magnitude and sign of $\Delta E_{\mathrm{Q}}$, and by the relative orientation of the induced spin and $V_{z z}$, the principal component of the electric field gradient tensor. In all these cases, $V_{z z}$ is perpendicular to the heme plane while $\langle S\rangle$ is induced in the heme plane. However, whereas $V_{z z}$ is positive for $\mathrm{Fe}(\mathrm{PPIXDME})\left(\mathrm{OC}_{6} \mathrm{H}_{4} \mathrm{NO}_{2}\right)$ and $\mathrm{Fe}(\mathrm{PPIXDME})\left(\mathrm{SC}_{6} \mathrm{H}_{4} \mathrm{NO}_{2}\right)$, the negative sign for $V_{z z}$ in Fe(PPIXDME) (OEt) results in the centroid of the $\Delta m=0$ lines being shifted in the opposite direction relative to the outer lines, compared with the former two compounds. From the variation of the overall magnetic splitting of the Mössbauer spectra versus the applied field $\mathbf{H}_{0}$ an estimate of $H_{\mathrm{hf}}^{0}$ can be obtained. However, since the magnetic hyperfine splitting is determined in general by the three constants, $D, E$, and $H_{\mathrm{hf}}^{0}$, magnetic moment measurements in high magnetic fields were also taken in order to obtain estimates of the parameters that simultaneously gave good fits to the Mössbauer and magnetization results. In the present case the orbital angular momentum is quenched i. e., $\langle\mathbf{L}\rangle=0$, and the observed magnetization at temperature $T$ is given by the thermal average of $2 \mu_{\beta}$ $\langle\alpha|\mathbf{S}| \alpha\rangle$ according to eq. (1), projected onto the direction of the magnetic field $\mathbf{H}_{0}$. For powder samples a spatial average over all directions of the magnetic field is required [17] which was carried out numerically. To ascertain convergence of the summation the same calculation was carried out for different numbers of discretely selected angles $\theta_{i}$ and $\varphi_{i}$ where $\theta$ and $\varphi$ determine the direction of $\mathbf{H}_{0}$ relative to the crystalline axes, with $\varphi$ being the azimuthal angle. For the range of the parameter values used angular increments of $\Delta \theta=2^{\circ}$ and $\Delta \varphi=10^{\circ}$ were sufficient to get convergent results.

In figure 4 the induced spin per iron atom (equal to $\frac{1}{2}$ the magnetic moment) is plotted versus the applied field for $\mathrm{Fe}(\mathrm{PPIXDME})\left(\mathrm{OC}_{6} \mathrm{H}_{4} \mathrm{NO}_{2}\right)$, $\mathrm{Fe}(\mathrm{PPIXDME})$ (OEt) and $\mathrm{Fe}(\mathrm{PPIXDME})\left(\mathrm{SC}_{6} \mathrm{H}_{4} \mathrm{NO}_{2}\right)$.

In figure $4 a$ the theoretical curves for $D=5 \mathrm{~cm}^{-1}$ and $10 \mathrm{~cm}^{-1}$ are also shown in order to indicate the sensitivity of the measurements to the magnitude of this parameter. In this case, $E=0$, in agreement with the epr results on this compound [9] which show $E / D \simeq 0$, i. e., axial symmetry. A good fit is also obtained in figure $4 b$ with $D=5.3 \pm 0.2 \mathrm{~cm}^{-1}$, and $E=0$. We were unable to obtain, within the above spin Hamiltonian formalism, a good fit to the experimental data for $\mathrm{Fe}$ (PPIXDME) $\left(\mathrm{SC}_{6} \mathrm{H}_{4} \mathrm{NO}_{2}\right)$ (Fig. $4 c$ ) over the 


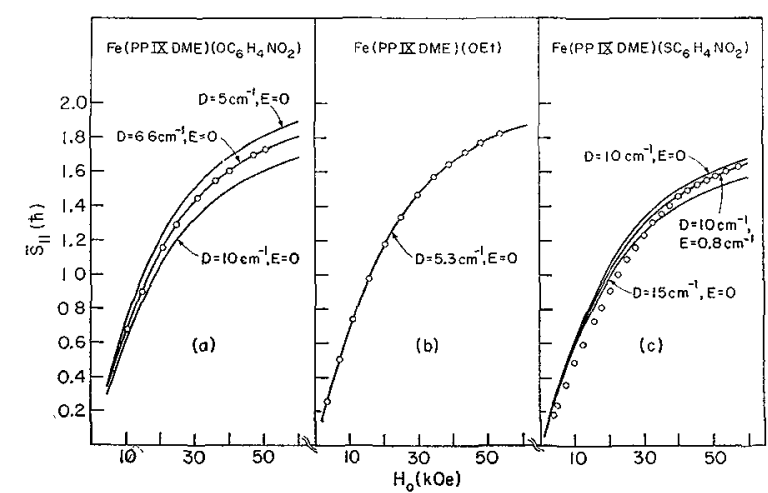

FIG. 4. - Magnetization data and theoretical fits at $4.2 \mathrm{~K}$. The magnetic moment in $\mu_{\mathrm{B}} / \mathrm{Fe}$ atoms is given by $\left.2 \overline{\mathrm{S}}_{\|}: a\right)$ The best fit is obtained for $D=6.6 \mathrm{~cm}^{-1}$ and $E=0$. Theoretical lines for $D=5 \mathrm{~cm}^{-1}$ and $D=10 \mathrm{~cm}^{-1}$ are also shown for comparison ; b) Best fit to experimental data is obtained for $D=5.3 \mathrm{~cm}^{-1}$ and $\left.E=0 ; c\right)$ At large applied fields the experimental points are best reproduced for $D=10 \mathrm{~cm}^{-1}$, $E=0.8 \mathrm{~cm}^{-1}$. At low applied fields the measured magnetization decreases faster than any reasonable values of $D$ and $E$ would predict.

whole range of magnetic field strengths used. For the related complex Fe(PPIXDME) $\left(\mathrm{SC}_{6} \mathrm{H}_{4} \mathrm{Cl}\right)$, epr measurements show non-axial zero field splitting with $E / D \sim 0.05$. For fields $\geqslant 40 \mathrm{kOe}$ (used for the Mössbauer work) a good fit could be obtained for $D=10 \mathrm{~cm}^{-1}$ and $E=0.8 \mathrm{~cm}^{-1}$, but values of $10 \leqslant D \leqslant 12 \mathrm{~cm}^{-1}$ and $E \leqslant 0.8 \mathrm{~cm}^{-1}$ also gave reasonable results. With lower values of $\boldsymbol{H}_{0}$, however, the observed magnetization was consistently lower than that calculated for all reasonable values of the parameters $D$ and $E$. This discrepancy might be due to the oversimplified spin Hamiltonian used or to an antiparallel exchange interaction between iron atoms in the crystalline matrix. Inclusion of contribution ${ }_{\mathrm{S}}$ from quartic order terms $S_{x}^{4}+S_{y}^{4}+S_{z}^{4}$ in the spin Hamiltonian might have improved the agreement between theory and experiment, but the effect of these terms is known to be small [18]. Nevertheless, the overall magnitude of the zero field splitting obtained from. the magnetization measurements of these compounds is consistent with the Mössbauer data and gives confidence in the magnitudes of the values of $H_{\mathrm{hf}}^{0}$ obtained.

In figure 5 we plot $\mathbf{H}_{\mathrm{hf}}$ as a function of the applied magnetic field for spectra obtained at $4.2 \mathrm{~K}$. The solid curves are theoretical, calculated for $\mathbf{H}_{0}$ in the heme plane and by making use of the values of $D$ obtained from the magnetization measurements and serve to determine values of $H_{\mathrm{hf}}^{0}$ which are tabulated in table $\mathrm{I}$.

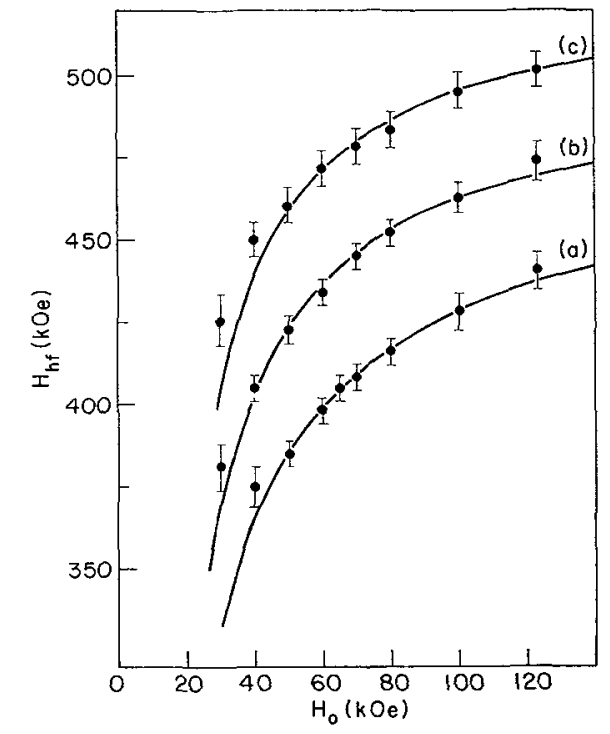

FIG. 5. - Observed hyperfine magnetic fields vs applied Ho. The solid lines give best theoretical fits to the experimental data for : a) $\mathrm{Fe}(\mathrm{PPIXDME})\left(\mathrm{SC}_{6} \mathrm{H}_{4} \mathrm{NO}_{2}\right), \quad D=10 \mathrm{~cm}^{-1}$, $H_{\mathrm{hr}}^{0}=-476$ kOe; b) Fe(PPIXDME) $\left(\mathrm{OC}_{6} \mathrm{H}_{4} \mathrm{NO}_{2}\right)$, $\left.D=6.6 \mathrm{~cm}^{-1}, H_{\mathrm{nr}}^{0}=-495 \mathrm{kOe} ; c\right) \mathrm{Fe}(P P I X D M E)(\mathrm{OEt})$, $D=5.3 \mathrm{~cm}^{-1}, H_{\mathrm{hr}}^{0}=-523 \mathrm{kOe}$.

We conclude that the saturation magnetic hyperfine field is sensitive to the nature of the axial ligand. The results show that anionic oxygen ligations result in $H_{\mathrm{hf}}^{0} \geqslant-500 \mathrm{kOe}$. Furthermore, measurements of acid-met Mb [19] have yielded $H_{\mathrm{hf}}^{0} \sim-500 \mathrm{kOe}$ (Table I). Thus, of the experimentally accessible and biologically viable alternatives, only thiolate sulfur coordination (in $\mathrm{Fe}$ (PPIXDME) $\left(\mathrm{SC}_{6} \mathrm{H}_{4} \mathrm{NO}_{2}\right)$ ) gives a value of $H_{\mathrm{hf}}^{0}$ significantly below $-500 \mathrm{kOe}$ and approaching that in ox-P-450.S. This result together with the magnetization and epr [9] evidence that oxygen ligation produces small or zero rhombicity whereas sulfur ligation results in a substantial rhombic distortion, points to thiolate sulfur for the axial ligand in the ox-P-450.S reaction state. This conclusion is further substantiated by other comparactive electronic properties of thiolate-bound $\mathrm{Fe}$ (III) porphyrins and the ox-P-450.S state [9], including most recently the results of MCD spectroscopy [20].

Acknowledgment. - This research was supported at the Department of Chemistry, Massachusetts Institute of Technology, by National Science Foundation Grant G. P.-40089X. The Francis Bitter National Magnet Laboratory is supported by the National Science Foundation.

\section{References}

[1] Ulrich, V., Angew. Chem. Int. Ed. 11 (1972) 701 ; Hul, H. A. O., RöDER, A. and WilliaMs, R. J. P., Struct. Bonding (Berlin) 8 (1970) 123.

[2] Gunsalus, I. C., Meeks, J. R., Lipscomb, J. D., DebrunNER, P. and MÜNCK, E., in Molecular Mechanisms of
Oxygen Activation, Hayaishi, O., Ed. (Academic Press, New York) 1973, Chapter 13.

[3] Sharrock, M., Debrunner, P. G., Schulz, C., LipsCOMb, J. D., Marshall, V. and Gunsalus, I. C.; Biochim. Biophys. Acta 420 (1976) 8; 
Sharrock, M., MÜNCK, E., Debrunner, P. G., Marshall, V., Lipscomb, J. D. and Gunsalus, I. C., Biochemistry 12 (1973) 258.

[4] Tsai, R., Yu, C. A., Gunsalus, I. C., Peisach, J., BuumBERG, W., ORME-JohnSON, W. H. and Beinert, H, Proc. Nat. Acad. Sci. USA 66 (1970) 1157.

[5] Mason, H. S., North, J. C. and Vanneste, M., Fed. Proc. 24 (1965) 1172.

[6] JefCoATE, C. R. E. and GAYLOR, J. L., Biochemistry 8 (1969) 3464.

[7] Bayer, E., Hull, H. A. O., Röder, A. and Williams, R. J. P., Chem. Commun. 109 (1969);

RöDer, A. and BAYER, E., Eur. J. Biochem. 11 (1969) 89.

[8] Tsai, R. L., Gunsalus, I. C. and Dus, K., Biochem. Biophys. Res. Commun. 45 (1971) 1300 ;

Dus, K., Litchfield, W. J., Miguel, A. G., vaN DER HoEven, I. A., Haugen, D. A., Dean, W. L. and Coon, M. J., Biochem. Biophys. Res. Commun. 60 (1974) 15.

[9] Tang, S. C., Koch, S., Papaefthymiou, G. C., Foner, S., Franker, R. B. and Holm, R. H., J. Am. Chem. Soc. 98 (1976) 2414.

[10] Hoard, J. L., in Porphyrins and Metalloporphyrins, Ed. K. M. Smith (Elsevier Publishing Co., Amsterdam) 1975, Chap. 8.
[11] Lang, G., Q. Rev. Biophys. 3 (1970) 1.

[12] Moss, T. H., Bearden, A. J. and Caughey, W. S., J. Chem. Phys. 51 (1969) 2624;

Maricondi, C., Straub, D. K. and Epstein, L. M., $J, A m$. Chem. Soc. 94 (1972) 4157 ;

Torrens, M. A., Straur, D. K. and Epstein, J., Am. Chem. Soc. 94 (1972) 4162.

[13] Btume, M., Phys. Rev. Lett. 18 (1967) 305.

[14] Sharma, R. R. and Moutsos. P., Phys. Rev. B 11 (1975) 1840.

[15] Weissbluth, M., Struct. Bonding (Berlin) 2 (1967) 1.

[16] Johnson, C. E., Phys. Lett. 21 (1969) 491 ;

Bleaney, B., Phil. Mag. 42 (1951) 441.

[17] Nakano, N., Otsuka, J. and Tasaki, A., Biochim. Biophys. Acta 236 (1971) 222.

[18] Abragam, A. and Pryce, M. H. L., Proc. R. Soc. (London) A 205 (1951) 135.

[19] BracketT, G. C., Richards, P. L. and Caughey, W. S., J. Chem. Phys. 54 (1971) 4383.

[20] Dawson, J. H., Holm, R. H., Trudell, J. R., ButK, G., LINDER, R. E., BRUenberG, E., DJerassi, C. and TANG, S. C., J. Amer. Chem. Soc. 98 (1976) 3707. 